\title{
CONGENITAL HEART DISEASE WITH ISOLATED INVERSION OF THE ABDOMINAL VISCERA
}

BY

\author{
PAUL FORGACS
}

From Guy's Hospital

Received September 6, 1946

The two cases reported illustrate an uncommon type of partial inversion of the viscera, in which the abdominal organs alone are transposed while the heart remains in its normal position. Both were suffering from congenital heart disease, and a subsequent search brought to light several further reports of cardiac malformation associated with a similar transposition of the viscera. This combination cannot, therefore, be regarded as fortuitous, and, in fact, a similar and well-recognized relationship exists between congenital heart disease and another variety of incomplete heterotaxy, in which the heart alone is transposed. Isolated dextrocardia is the subject of two recent reviews, based on large series of cases collected from the literature (Roesler, 1930, and Lichtman, 1931); case reports of heart disease in the presence of isolated inversion of the abdominal viscera are, on the other hand, scanty and so far have not been critically reviewed.

\section{CASE REPORTS}

Case 1. 'An Army officer, aged 25 years, was admitted to Guy's Hospital in April 1946 for investigation. Suspicion about his heart arose two years earlier, when a routine radiogram of his chest showed a large heart. His capacity for exercise was normal; in fact, during the previous five years he had undergone several periods of very strenuous training without undue distress. There was no history of cyanosis and he had never suffered from rheumatic fever.

He was a well-developed fit-looking man, and was able to take vigorous exercise without dyspnœa. There was no cyanosis or clubbing of the fingers. He was apyrexial and his resting heart rate varied between 50-60, with striking sinus arrhythmia. Owing to this the blood pressure readings were somewhat variable and averaged $145 / 50$. A very forcible apex beat was found $2.5 \mathrm{~cm}$. outside the mid-clavicular line. A moderately loud, rough systolic murmur was audible in the second left intercostal space close to the sternum, cońducted along that space, as well as to the back, just medially to the left scapula. The pulmonary second sound was accentuated and high pitched. The heart sounds were otherwise normal.

All other clinical findings were normal, except that the liver dullness was found in the left hypochondrium, while the right hypochondrium was resonant. Blood pressure readings in the lower limbs were equal to those in the arms and no anastomotic arteries were palpable over the chest wall.

$X$-ray findings. In the postero-anterior view (Fig. 1A) the heart was enlarged both to the left and to the right, with a maximum transverse diameter of $16 \mathrm{~cm}$. in a chest of $29 \mathrm{~cm}$. The convexity of the apical region suggested enlargement of the left ventricle, but the pulmonary conus was also abnormally prominent and the branches of the pulmonary artery, especially the right descending, were strikingly distended. The ascending aorta was displaced to the right; its right border lay $3.5 \mathrm{~cm}$. from the mid-line. The gas bubble in the stomach was visible under the right diaphragm. On screening the lower third of the left border of the heart showed marked pulsation; systolic excursion in the region of the conus was also excessive, but no abnormal pulsation was visible in the hilar vessels. 

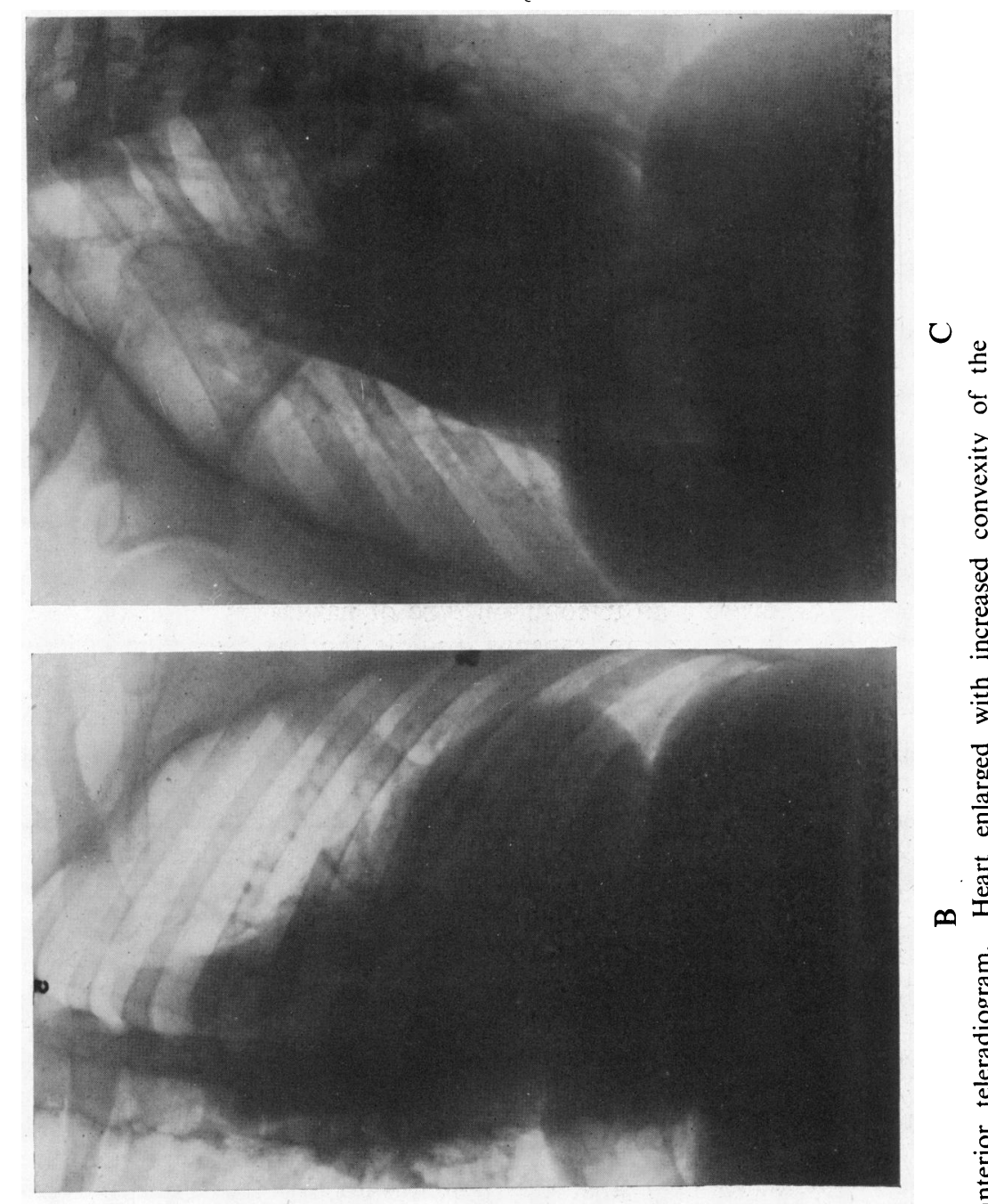

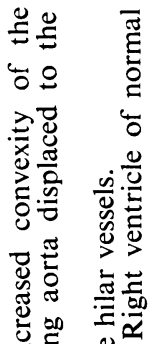

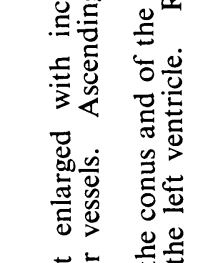

호 호

$\infty$
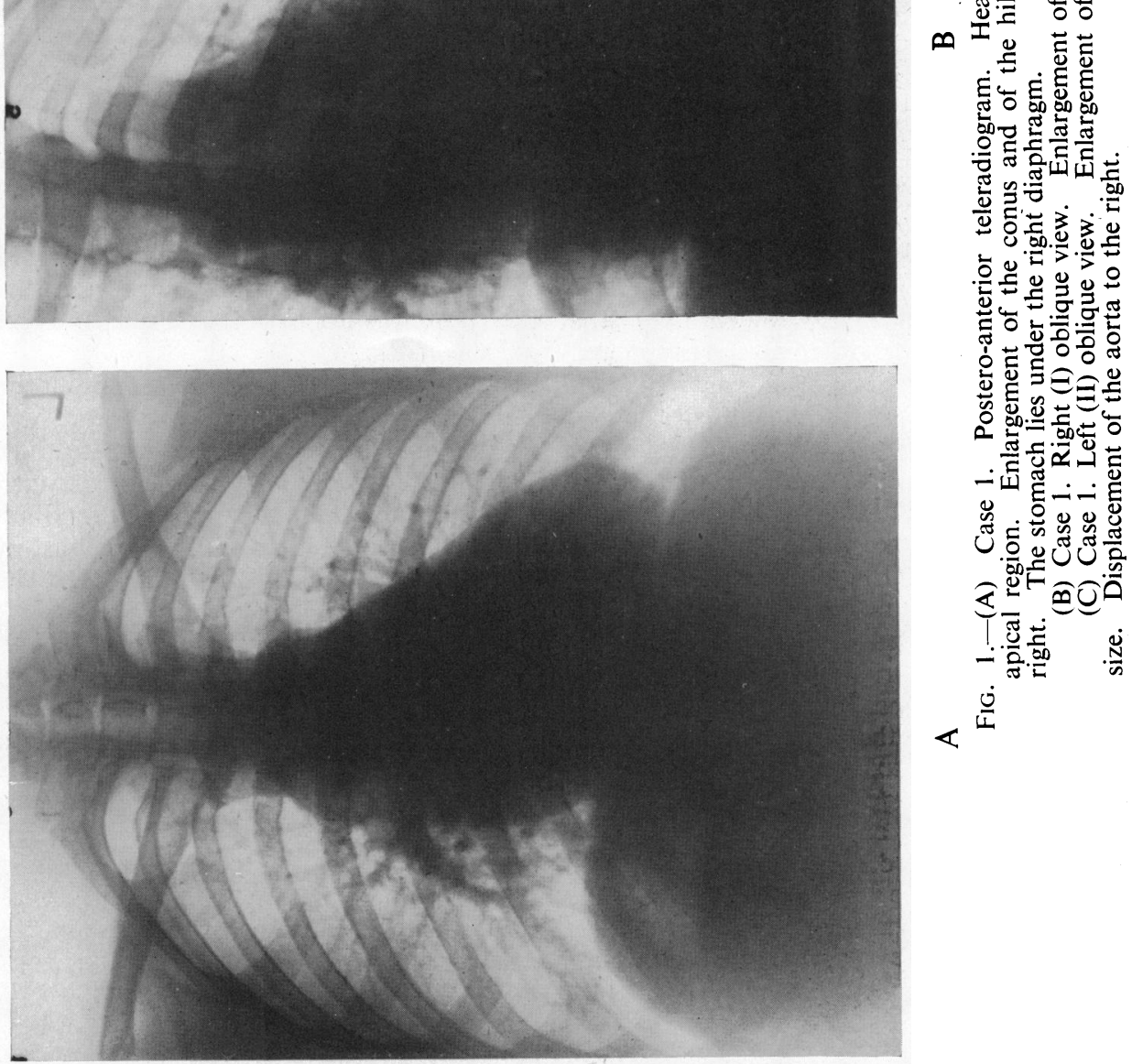
The right (I) oblique view (Fig. 1B) confirmed the abnormal prominence of the pulmonary conus. The most striking feature of the left (II) oblique view (Fig. 1C) was bulging of the left border of the ventricular shadow, while the right border was, by contrast within normal limits.

The electrocardiogram (Fig. 2) showed sinus arrythmia, left axis deviation, and inversion of P II, P III, and T III.

Diagnosis. In view of the apparent enlargement of the left ventricle and the left axis deviation, the possibility of aortic regurgitation, sub-aortic stenosis, coarctation of the aorta, or of hypertension was considered, but no further evidence was found in favour of any of these conditions.

The prominence of the pulmonary conus, the widening of the main branches of the pulmonary artery, the forcible pulsation of the apex and of the conus, and the systolic murmur in the second left intercostal space with accentuation of the pulmonary second sound are in keeping with the diagnosis of an atrial septal defect. Left ventricular enlargement and left axis deviation are, on the

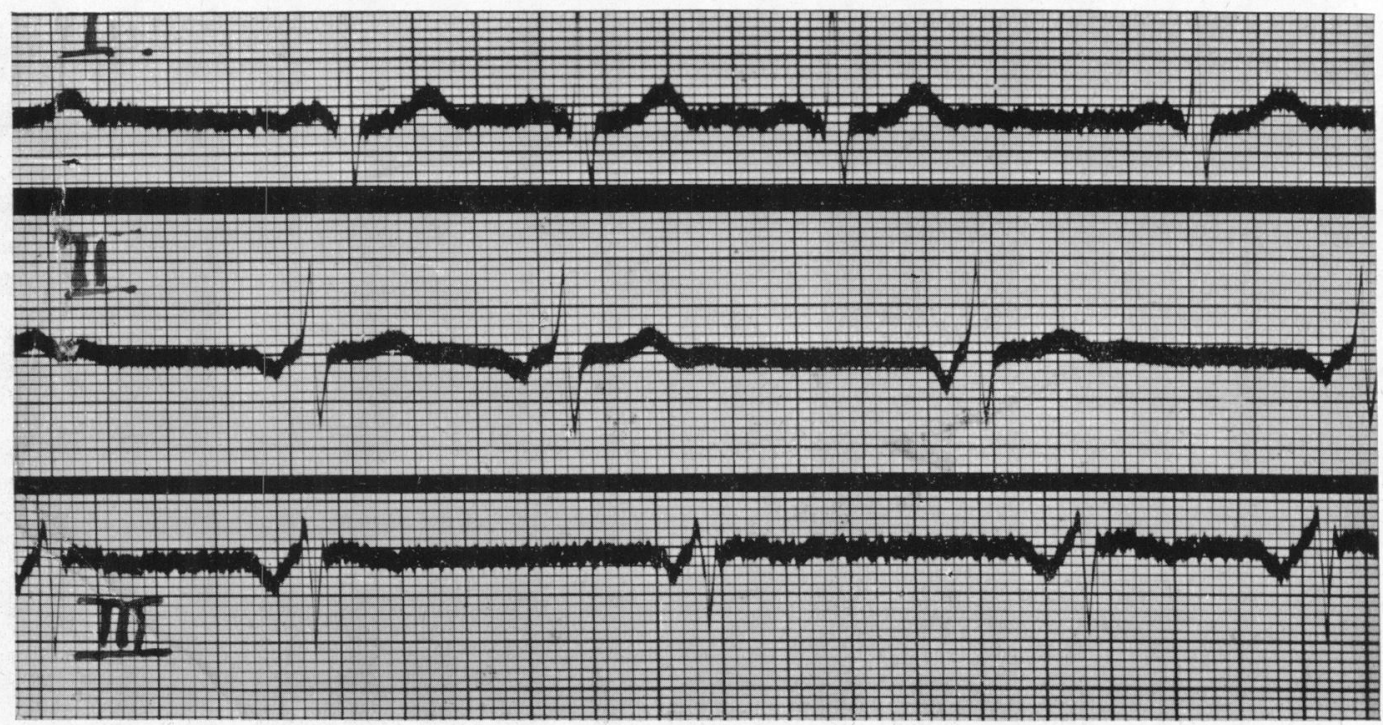

Fig. 2.-Case 1. Electrocardiogram, showing sinus arrhythmia, left axis deviation, inversion of $\mathbf{P}$ II, $P$ III, and T III.

other hand, exceptional: in fact enlargement of the right ventricle and right axis deviation were found to be the rule in a series of 53 cases analysed by Bedford et al. (1940). A possible explanation of the anomaly is that in this case the ventricles are transposed and that the aorta, which is displaced towards the right, originates from an arterial right ventricle, the whole of the left border of the heart being formed by a venous left ventricle.

Some of the clinical findings, taken separately, would fit the diagnosis of pulmonary stenosis or of patent ductus arteriosus, but the evidence as a whole is against these, and the preponderance of the left ventricle would still remain unexplained. The most likely diagnosis is, therefore, patency of the atrial septum with corrected transposition of the great vessels, although it must remain speculative.

Case 2. A boy, aged 5 years, was admitted to the County Hospital, Farnborough, in May 1945, suffering from intestinal obstruction. He had been deeply cyanosed from birth, and clubbing of the fingers and toes had been present since early childhood. His capacity for exercise had always been much below normal.

On laparotomy he was found to have an ileo-cæcal intussusception, associated with non-rotation of the mid-gut. The cæcum was under the liver in the left upper compartment of the abdomen and the rest of the large intestine was displaced into the right half of the peritoneal cavity. The stomach was displaced to the right, and, as a later barium meal (Fig. 3) showed, its position was a mirror 
image of the normal. Further details of the disposition of the abdominal viscera were published by van Meurs (1946).

The heart was moderately enlarged, with the apex beat $2 \mathrm{~cm}$. outside the mid-clavicular line, and a strip of dullness for a distance of $1.5 \mathrm{~cm}$. to the right of the sternum. A loud, rasping systolic murmur was heard over a wide area of the præcordium, with its maximum intensity in the third left intercostal space. The blood pressure was $90 / 60$. The red cell count was $8 \cdot 1$ million with the hæmoglobin 130 per cent.

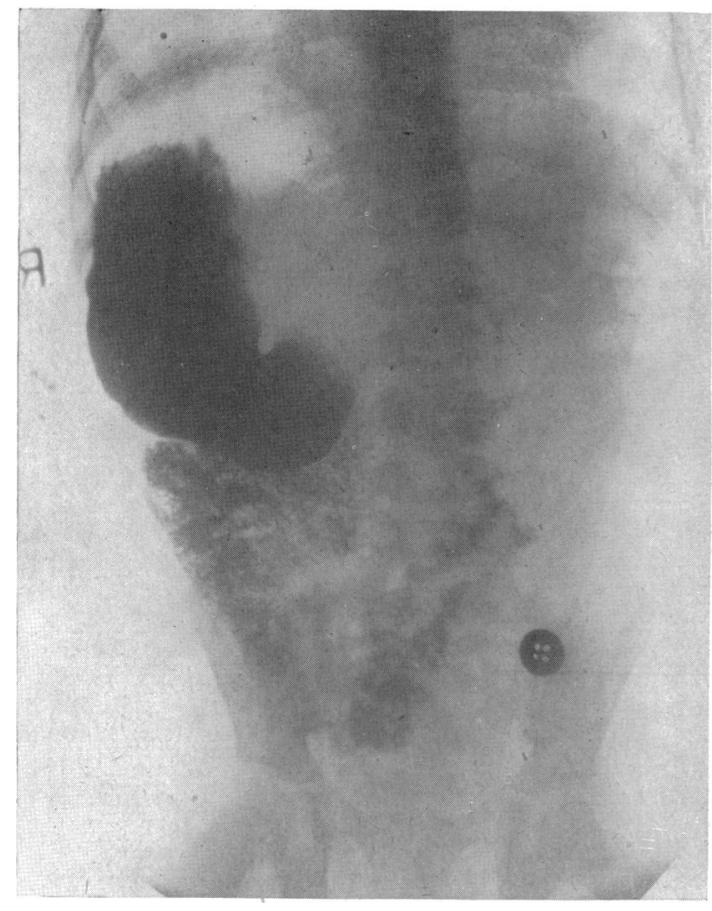

Fig. 3.-Case 2. Barium meal, showing reversed position of the stomach and jejunum.

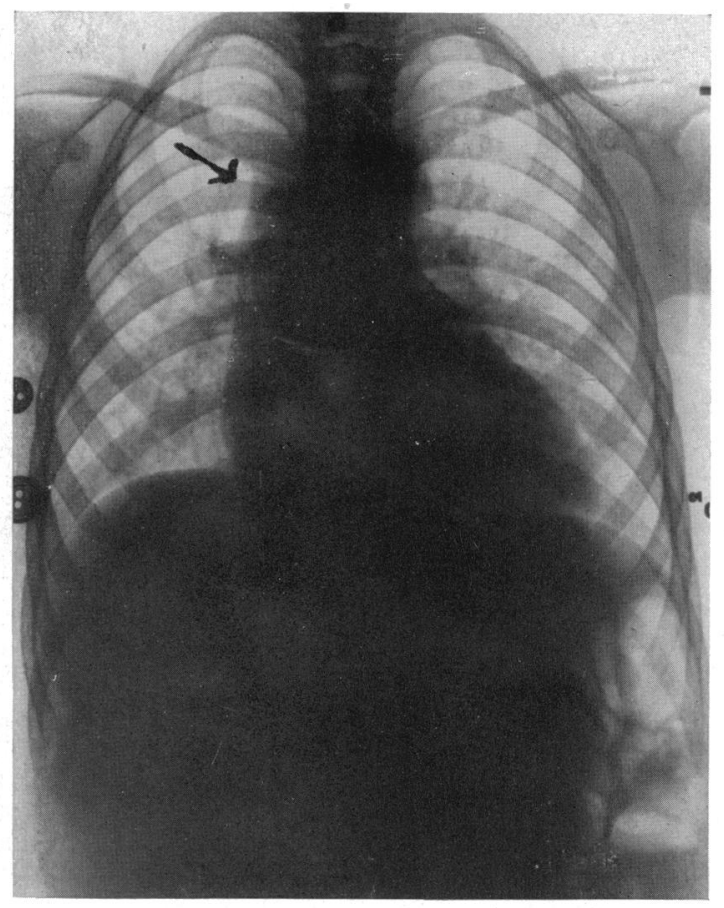

FIG. 4.-Case 2. Postero-anterior teleradiogram. Cœur en sabot. Displacement of the aorta to the right. Double aortic arch.

$X$-ray findings. (Fig. 4.) The heart was moderately enlarged with a maximum transverse diameter of $11.5 \mathrm{~cm}$. It was slightly displaced to the right: the right border of the ascending aorta was $4.5 \mathrm{~cm}$. from the mid-line and part of the aortic arch appeared to the right of the trachea. $1.5 \mathrm{~cm}$. higher, to the left of the trachea, there was another semicircular shadow, which possibly represented a second aortic arch.

Diagnosis. The deep cyanosis dating back to birth, with polycythæmia and clubbing of the fingers, is evidence of a congenital cardiac defect, with free mixing of blood between the right and left chambers. In view of the shape of the heart, the displacement of the aorta towards the right, and the loud systolic murmur in the third left intercostal space, the diagnosis of Fallot's tetralogy is highly probable.

\section{SuMMARY OF REPORTED CASES AND DisCuSSION}

A search produced only 12 further reported cases of congenital heart disease associated with isolated inversion of the abdominal viscera. Details of these are shown in Table I.

It would be unwise in this small series of cases to base an estimate of the total incidence 
TABLE I

\begin{tabular}{|c|c|c|c|c|}
\hline Author & Age and Sex & Type of Heart Disease & Abdominal Viscera & Autopsy \\
\hline $\begin{array}{l}\text { Breschet (1826) } \\
\text { quoted by Gruber }\end{array}$ & 6 weeks, M. & Cor biloculare & $\begin{array}{l}\text { Stomach on the right. } \\
\text { Liver central }\end{array}$ & Yes \\
\hline Hickman (1869) & 6 weeks, M. & $\begin{array}{l}\text { Atria transposed } \\
\text { Corrected transposition of the } \\
\text { arterial trunks } \\
\text { Patent atrial septum } \\
\text { Patent ventricular septum } \\
\text { Patent ductus arteriosus }\end{array}$ & Transposed & Yes \\
\hline $\begin{array}{l}\text { Marchand (1883) } \\
\text { quoted by Gruber }\end{array}$ & 1 day, ? & Cor triloculare biventriculare. & $\begin{array}{l}\text { Stomach on the right. } \\
\text { Liver on the right }\end{array}$ & Yes \\
\hline $\begin{array}{l}\text { Griffith (1897) } \\
\text { quoted by Licht- } \\
\text { man }\end{array}$ & 9 months, $\mathrm{M}$. & $\begin{array}{l}\text { Atria transposed } \\
\text { Transposition of the arterial } \\
\text { trunks } \\
\text { Patent ventricular septum } \\
\text { Patent ductus arteriosus } \\
\text { Pulmonary stenosis }\end{array}$ & Transposed & Yes \\
\hline Lochte (1898) & 17 years, $M$. & $\begin{array}{l}\text { Atria transposed } \\
\text { Transposition of the arterial } \\
\text { trunks } \\
\text { Patent atrial septum } \\
\text { Patent ventricular septum } \\
\text { Pulmonary stenosis }\end{array}$ & $\begin{array}{l}\text { Stomach on the right. } \\
\text { Liver central. The } \\
\text { left lobe larger } \\
\text { than the right lobe }\end{array}$ & Yes \\
\hline $\begin{array}{l}\text { Geipel (1899) } \\
\text { quoted by Schelenz }\end{array}$ & Unknown & $\begin{array}{l}\text { Atria transposed } \\
\text { Aorta and pulmonary artery } \\
\text { originate from the right ven- } \\
\text { tricle }\end{array}$ & $\begin{array}{l}\text { Stomach on the right. } \\
\text { Liver on the right }\end{array}$ & Yes \\
\hline $\begin{array}{l}\text { Hingst (1901) } \\
\text { quoted by Schelenz }\end{array}$ & Unknown & $\begin{array}{l}\text { Patent atrial septum } \\
\text { Patent ventricular septum }\end{array}$ & $\begin{array}{l}\text { Spleen, liver, and } \\
\text { stomach on the } \\
\text { right }\end{array}$ & Yes \\
\hline McCrae (1905) & 49 days, $M$. & $\begin{array}{l}\text { Atria transposed } \\
\text { Patent atrial septum } \\
\text { Patent ductus arteriosus } \\
\text { Pulmonary atresia } \\
\end{array}$ & Transposed & Yes \\
\hline $\begin{array}{c}\text { Royer and Wilson } \\
(1908)\end{array}$ & $6 \frac{1}{2}$ years, $M$ & $\begin{array}{l}\text { Atria transposed } \\
\text { Patent atrial septum } \\
\text { Patent ventricular septum }\end{array}$ & Transposed & Yes \\
\hline Knape (1912) & 8 days, $M$. & $\begin{array}{l}\text { Cor triloculare biatrium } \\
\text { Atrial septal defect } \\
\text { Pulmonary atresia } \\
\text { Patent ductus arteriosus }\end{array}$ & Transposed & Yes \\
\hline $\begin{array}{c}\text { Shaw and Blake } \\
(1924)\end{array}$ & 2 years, $M$. & Patent ventricular septum & Transposed & No \\
\hline Miller (1925) & 10 weeks, $F$. & $\begin{array}{l}\text { Atria transposed } \\
\text { Patent atrial septum } \\
\text { Patent ductus arteriosus } \\
\text { Pulmonary artery and aorta } \\
\text { arise from left ventricle }\end{array}$ & Transposed & Yes \\
\hline
\end{tabular}


of congenital heart disease, or of the relative frequency of the various types of cardiac defect in isolated inversion of the abdominal viscera. Although there are numerous surgical reports of transposition of the abdominal organs, the heart in these cases has not, as a rule, been examined with sufficient care to reveal minor abnormalities. Also, in the days before radiological study of heart disease was adopted, the abnormal position of the stomach is likely to have been often overlooked. For this reason, the prevalence of post-mortem records of severe heart lesions in this series may well give an unduly gloomy impression of this condition.

The prevalence of transposition of the atria is, however, very striking. Out of the 14 cases (including the 2 here reported) this otherwise rare abnormality was present in 8 cases: 2 of the remaining 6 had a common atrium supplying both ventricles, and in 4 the disposition of the atria could not be ascertained. It appears probable that this abnormality constitutes the key defect of the heart, the associated structural changes merely serving to direct the arterial and venous return to the heart into their correct outflow channels. Of the mechanisms by which this might be achieved, transposition of the aorta into the right ventricle and of the pulmonary artery into the left ventricle is alone completely effective. All other types of defect, such as patency of the septa or of the ductus arteriosus, merely provide for admixture of arterial to the venous blood of the systemic outflow, and are, therefore, incompatible with prolonged survival. In effect, in the whole series only two cases survived to adult age (Lochte, 17 years, and Forgacs, 26 years); in these subjects corrected transposition of the arterial trunks was diagnosed by post-mortem examination in the first, and on clinical grounds in the second. Of the remaining 12 cases, 6 died in the first few weeks of life and none of the others was over the age of seven at the time of observation.

The remarkable prevalence of transposition of the atria may offer a clue to the pathogenesis of the congenital heart lesions in this group and also in the very similar group of isolated dextrocardia. This type of heterotaxy, which is the exact reverse of the visceral arrangement under discussion, is nearly always complicated by congenital malformations of the heart. Lichtman (1931), in his survey of 161 reported cases of isolated dextrocardia, found only 3 examples of anatomically normal hearts. An interesting and significant fact emerges from Roesler's (1930) detailed analysis of 24 cases of isolated dextrocardia: the inferior vena cava terminated in the right atrium in 16 of the 18 in which the relevant data were available.

In an ideal mirror picture dextrocardia the vena cava runs into the left atrium; an arrangement which is the rule when both the heart and the abdominal viscera are transposed. In this group, as is well known, the heart is nearly always free from structural defect. If we accept such cases as the standard of the normal right-sided heart, it will be apparent that in Roesler's series the position of the atria is reversed. It may be stated, therefore, that when the abdominal viscera alone or the heart alone is transposed to the opposite side of the body, the arrangement of the atria is usually the reverse of the normal.

The similarity between the two groups of cases suggests a common pathogenesis of the cardiac defects. Of the many explanations put forward to account for the malformation of the heart in isolated dextrocardia, those which explain it as a result of torsion (Pal, 1907) or those which assume the heart lesions to be primary and the transposition of the heart as an effect of these (Monckeberg, 1915) are clearly not applicable to isolated transposition of the abdominal viscera, in which the heart remains in its normal position. A satisfactory hypothesis, valid for both groups, must take into account the abnormal relative position of the abdominal viscera and the heart. The only conceivable mechanism by which the position of the abdominal organs might influence the structure of the heart is through the agency of the embryonic abdominal venous channels.

To make the argument clearer, it is useful to recall that the original symmetry of the 
sinus venosus of the embryo is later destroyed by the disproportionately rapid increase in size of the right horn of the sinus. This structure is subsequently incorporated into the primitive atrium and eventually forms part of the right atrium of the mature fœtus. The rapid growth of the right horn of the sinus is determined by the development of transverse anastomoses in the abdominal venous channels shunting blood from the left side of the abdomen to the veins on the right, which terminate in the right horn of the sinus. Finally the veins on the left disappear, and the whole of the inflow from the liver and the placenta is delivered into the right atrium by way of the vena hepatis communis. This vein is later incorporated into, and forms, the terminal portion of the inferior vena cava.

It is clear, therefore, that the abdomina venous channels of the embryo have a profound influence in determining the development of the atria. It seems probable that the reversal of the normal relationship between the heart and the liver in the two varieties of incomplete heterotaxy is associated with a corresponding change in the hepatic venous channels; a possibility discussed in detail by Lochte (1898). In the event of such a change the "left" horn of the sinus venosus would receive the venous return from the liver and placenta, and in the course of embryonic development, the inferior vena cava would come to terminate in the "left" atrium.

The transposition of the atria, which may be regarded as the fundamental defect in most cases of isolated inversion of the abdominal viscera and of isolated dextrocardia, is then a necessary sequel of the reversed connection between the abdominal veins and the sinus venosus. The associated malformations of the heart occur, as already suggested, as a result of the faulty development of the cardiac septa, or of an incomplete torsion of the aortopulmonary septum, in an attempt to divert the venous return into its correct outflow channel.

\section{SUIMMARY}

Two cases of congenital heart disease associated with isolated inversion of the abdominal viscera are described, together with a summary of similar cases that have been reported.

An attempt is made to correlate the findings in this group with those in isolated dextrocardia.

I am indebted to Dr. Maurice Campbell, under whose care Case 1 was investigated, for much help and encouragement. My thanks are also due to Dr. J. F. Hackwood, Medical Superintendent of the County Hospital, Farnborough, for his permission to report Case 2, and to Mr. D. P. van Meurs for his kindness in lending me his records of the laparotomy findings.

\section{REFIRENCES}

Bedford, D. E., Papp, C., Parkinson, J. (1941). Brii. Heart. J., 3, 37.

Gruber, W. (1865). Arch. Anat. Physiol., Leipzig, p. 583.

Hickman, W. (1869). Trans. path. Soc., London, $20,88$.

Knape, W. (1912). Virchows Arch., $209,473$.

Lichtman, S. S. (1931). Arch. intern. Med., 48, 683.

Lochte (1898). Beitr. path. Anat., 24, 187.

McCrae, J. (1905). J. Anat., London, 40, 28.

Miller, A. J. (1925). Amer. J. Path., 1, 467.

Monckeberg, J. C. (1915). Quoted by Lichtman (1931).

Pal, J. (1907). Z Zbl. Herz Gefasskr., 11, 249.

Roesler, H. (1930). Wien. Arch. inn. Med., 19, 505.

Royer, B. F., Wilson, J. D. (1908). Arch. Pediat., 25, 881.

Schelenz, C. (1909). Berl. klin. Wschr., 46, 788.

Shaw, E., and Blake, H. K. (1924). Amer. J. Dis. Child., 28, 204.

van Meurs, D. P. (1946). Brit. J. Surg., 34, 91. 